Research Article

\title{
Association between skinfold thickness and neck circumference with anemia in rural school going adolescent girls
}

\author{
Saiprasad Kavthekar*, Ashok Chougule, Anil Kurane, Devayani Kulkarni
}

Department of Pediatrics, Dr. D.Y. Patil Medical College and Hospital Kadamwadi, Kolhapur, Maharashtra, India

Received: 10 June 2016

Accepted: 02 July 2016

*Correspondence:

Dr. Saiprasad Kavthekar,

E-mail: saiprasadka@yahoo.co.in

Copyright: (c) the author(s), publisher and licensee Medip Academy. This is an open-access article distributed under the terms of the Creative Commons Attribution Non-Commercial License, which permits unrestricted non-commercial use, distribution, and reproduction in any medium, provided the original work is properly cited.

\begin{abstract}
Background: Anemia is one of the most common hematological abnormalities found in children and adolescents. Unfortunately assessment of nutritional status of adolescent girls has been the least explored area of research, particularly in rural India. There are studies which associated Body Mass Index and anemia in adolescent girls. But the validity of BMI across diverse samples of youth has not been evaluated. Objective of this study was to study association between skinfold thickness and neck circumference with anemia in rural school going adolescents.

Methods: A prospective study was carried out among 1200 rural adolescent girls of 10 randomly selected government schools (120 girls from each school and from each class 30 girls) between the age group of 12-16yrs. Skin fold thickness was measured by Herpenden's caliper. Neck circumference was measured. The hemoglobin levels were estimated by cyanmethemoglobin method by finger prick. The collected data was statistically analysed.

Results: The prevalence of anemia in rural school going adolescent girls was 54.2\%.91.3\% adolescent girls had SFT $<14.5 \mathrm{~mm}$, out of that $56.2 \%$ adolescent girls were significantly anemic. $25.1 \%, 30.3 \%$ and $0.7 \%$ suffered significant mild, moderate and severe anemia respectively. $84.4 \%$ adolescent girls had neck circumference $<27 \mathrm{cms}$, out of that $58.4 \%$ girls had significant anemia $(24.2 \%$ mild, $33.4 \%$ moderate and $0.9 \%$ severe anemia).

Conclusions: The adolescent girls who had SFT $<14.5 \mathrm{~mm}$ and neck circumference $<27 \mathrm{cms}$ suggesting undernutrition were significantly anemic. SFT and NC can be used as nutritional parameter in adolescent girls. The health and nutritional education should be advocated to rural adolescent girls.
\end{abstract}

Keywords: Adolescent girls, Anemia, Neck circumference, Skinfold thickness

\section{INTRODUCTION}

Anemia is one of the most common hematological abnormalities found in children and adolescents. It is defined as a low level of hemoglobin in the blood. It is one of the world's most widespread nutritional problem. ${ }^{1}$ India has the world's highest prevalence of iron deficiency anemia among women with $60-70 \%$ of the adolescent girls being anemic. ${ }^{2}$ Anemia in adolescent girls has far reaching implications. The anemic adolescent girls grow into adult women with compromised growth, both physical and mental. These women have low pre-pregnancy weight and are more likely to die during childbirth and deliver low birth weight babies. ${ }^{3,4}$ Adolescent girls form a crucial segment of the population and constitute, as it were, the vital bridge between the present generation and the next. Unfortunately assessment of nutritional status of adolescent girls has been the least explored area of research, particularly in rural India. There are various studies, in which Body Mass Index was associated with anemia in adolescent girls. ${ }^{5-8}$ However, the BMI has limitations; it tends to have high specificity, but low and variable sensitivity in children and adolescents. Further, the validity of BMI across diverse samples of youth has not been evaluated. ${ }^{9}$ So we tried to associate other nutritional parameters like Skinfold thickness (SFT) and 
Neck circumference (NC) with anemia in rural school going adolescent girls.

\section{METHODS}

This prospective study was conducted in 10 government schools of rural Kolhapur, among 1200 adolescent girls. Schools were chosen randomly and from each school 120 adolescent girls and from each class 30 adolescent girls were selected randomly from attendance register. The girls between the age group 12-16yrs were selected for the study. The study was carried out after approval by Institutional ethical committee and permission from school principal/ headmaster. Informed consent from parents/ guardian was also taken. A specially designed data entry format was used to enter all adolescent girl's details like name, age, school, standard, skinfold thickness, neck circumference and haemoglobin level. Tricep skinfold thickness (SFT) was measured on right side with relaxed shoulder and arms hanging freely at the sides in standing position. Skin is pinched using both index finger and skinfold thickness was measured with herpendens caliper. Neck circumference (NC) was measured in the midway of the neck, between midcervical spine and mid anterior neck, to within $1 \mathrm{~mm}$, using non stretchable plastic tape with the girls standing upright. Hemoglobin level was determined by cyanmet hemoglobin method by finger prick on the same day of sample collection. ${ }^{10}$ As per WHO recommendations anaemia was diagnosed when $\mathrm{Hb}<12 \mathrm{~g} / \mathrm{dL}$ in $10-18$ years girls. ${ }^{11}$ The severity of anaemia was graded as mild $(\mathrm{Hb}$ $>10 \mathrm{~g} / \mathrm{dL}$ ), moderate ( $\mathrm{Hb}$ 7-9.9 g/dL) and severe ( $\mathrm{Hb}$ $<7 \mathrm{~g} / \mathrm{dL}) .^{12}$ All observations were recorded, tabulated and subjected to statistical analysis by chisquare test in which $\mathrm{P}<0.05$ was significant. $\mathrm{P}$ value was determined by using the primer of biostatistics and MS EXCEL 2007.

\section{RESULTS}

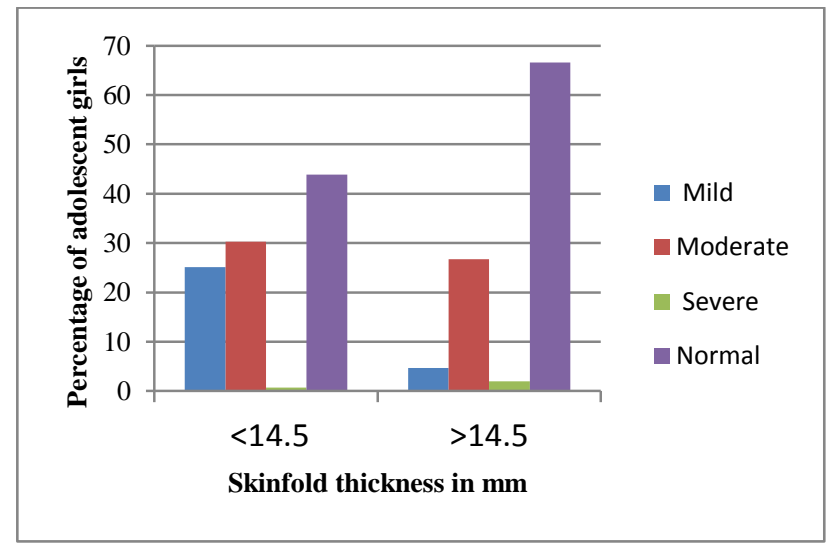

$\left(X^{2}=29.917\right.$ with 3 degrees of freedom; $\left.P=0.000\right)$.

\section{Figure 1: Association between skinfold thickness and severity of anemia.}

The prevalence of anemia in rural school going adolescent girls was $54.2 \%$ (Table 1). $23.4 \%, 30 \%$ and
$0.8 \%$ adolescent girls suffered from mild, moderate and severe anemia (Table 2).91.3\% rural adolescent girls had skin fold thickness $<14.5 \mathrm{~mm}$ and $8.7 \%$ had $>14.5$ mm.56.2\% adolescent girls who had skin fold thickness $<14.5 \mathrm{~mm}$ were significantly anemic compared to $33.4 \%$ in whom skin fold thickness $>14.5 \mathrm{~mm}$ (Table 3). The adolescent girls who had skin fold thickness $<14.5 \mathrm{~mm}$ suffered significantly $25.1 \%$ mild, $30.3 \%$ moderate and $0.7 \%$ severe anemia (Figure 1).

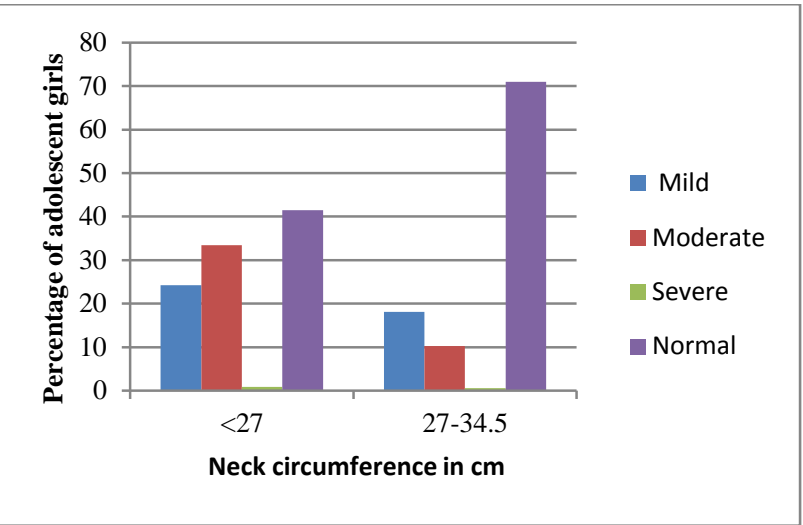

$\left(\mathrm{X}^{2}=57.951\right.$ with 3 degrees of freedom; $\left.\mathrm{P}=0.000\right)$.

Figure 2: Association between neck circumference and severity of anemia.

Table 1: Prevalence of anemia in rural adolescent girls.

\begin{tabular}{|lllllll|}
\hline \multirow{2}{*}{$\begin{array}{l}\text { Age in } \\
\text { years }\end{array}$} & \multicolumn{2}{l}{ Adolescent girls } \\
\cline { 2 - 7 } & Anemic & \multicolumn{2}{ll}{ Non anemic } & Total \\
\cline { 2 - 7 } & No & $\%$ & No & $\%$ & No & $\%$ \\
\hline $12-13$ & 138 & 46 & 162 & 54 & 300 & 100 \\
\hline $13-14$ & 190 & 63.3 & 110 & 36.7 & 300 & 100 \\
\hline $14-15$ & 172 & 57.4 & 128 & 42.6 & 300 & 100 \\
\hline $15-16$ & 150 & 50 & 150 & 50 & 300 & 100 \\
\hline Total & 650 & 54.2 & 550 & 45.8 & 1200 & 100 \\
\hline
\end{tabular}

Table 2: Severity of anemia in rural adolescent girls.

\begin{tabular}{|lll|}
\hline Hemoglobin $(\mathrm{g} / \mathrm{dl})$ & No. of cases & Percentage $\%$ \\
\hline$>12$ Normal & 550 & 45.8 \\
\hline 10-12 Mild anemia & 280 & 23.4 \\
\hline 7-10 Moderate anemia & 370 & 30.0 \\
\hline Below 7 severe anemia & 10 & 0.8 \\
\hline Total & 1200 & 100 \\
\hline
\end{tabular}

$84.4 \%$ adolescent girls had neck circumference $<27 \mathrm{cms}$, out of that $58.4 \%$ girls had significant anemia as compared to girls whose neck circumference was 27-34.5 cms (Table 4).

The girls in whom neck circumference was $<27 \mathrm{cms}$ suffered significantly $24.2 \%$ mild, $33.4 \%$ moderate and $0.9 \%$ severe anemia (Figure 2 ). 
Table 3: Association between skinfold thickness and anemia.

\begin{tabular}{|lllll|}
\hline & \multicolumn{4}{l}{ Skin fold thickness } \\
\cline { 2 - 5 } & $<14.5$ & & $>14.5$ \\
& no & $\%$ & no & $\%$ \\
\hline anemic & 615 & 56.2 & 35 & 33.4 \\
\hline non anemic & 480 & 43.8 & 70 & 66.6 \\
\hline total & 1095 & 91.3 & 105 & 8.7 \\
\hline
\end{tabular}

$\left(\mathrm{X}^{2}=19.208\right.$ with 1 degree of freedom; $\left.\mathrm{P}=0.000\right)$.

Table 4: Association between neck circumference and anemia.

\begin{tabular}{|lllll|}
\hline \multirow{4}{*}{} & \multicolumn{4}{l}{ Neck circumference in cm } \\
\cline { 2 - 5 } & $<27$ & \multicolumn{3}{l|}{$27-34.5$} \\
\cline { 2 - 5 } & no & $\%$ & no & $\%$ \\
\hline anemic & 599 & 58.4 & 51 & 29 \\
\hline non anemic & 425 & 41.6 & 125 & 71 \\
\hline total & 1024 & 85.4 & 176 & 14.6 \\
\hline
\end{tabular}

$\left(\mathrm{X}^{2}=51.530\right.$ with 1 degree of freedom; $\left.\mathrm{P}=0.000\right)$.

\section{DISCUSSION}

In our study the overall prevalence of anemia in rural school going adolescent girls was reported to be $54.2 \%$. Chitra B et al, Peter etal and Rawat et al observed prevalence of anemia as $81.7 \%, 77.9 \%$ and $40.8 \%$ respectively in rural adolescent girls. ${ }^{13-15}$ National Family health Survey (NFHS) New Delhi observed 56\% of adolescent girls were anemic and stated that adolescence in India goes hand in hand with iron deficiency anemia. Agarwal etal observed $77.2 \%$ adolescent girls were anemic out of that $45.5 \%, 28.2 \%$ and $3.5 \%$ suffered mild, moderate and severe anemia respectively. ${ }^{16,17}$ According to WHO if the prevalence of anemia at community is more than $40 \%$, it is considered as a problem of high magnitude. ${ }^{18}$

Deshpande et al studied SFT and NC as nutritional parameter in adolescent girls, and observed 95\% and $81.7 \%$ adolescent girls had SFT $<14.5 \mathrm{~mm}$ and $\mathrm{NC}<27 \mathrm{~cm}$ respectively which was the sign of under nutrition. ${ }^{19}$ $62.8 \%$ and $63.6 \%$ adolescent girls were anemic whose $\mathrm{SFT}<14.5 \mathrm{~mm}$ and $\mathrm{NC}<27 \mathrm{~cm}$ respectively. $6.1 \%$ and $42.4 \%$ adolescent girls were anemic whose SFT $>14.5 \mathrm{~mm}$ and $\mathrm{NC}>27 \mathrm{~cm}$ respectively. These results are comparable to our study results. Reilly et al used SFT as a parameter to measure body composition in pre pubertal children. Patnaik et al used NC as one of the nutritional parameter in overweight adolescents. ${ }^{20,21}$ In adults, SFT had been shown to be as valid as any other method for the measurement of absolute fat mass and fat free mass. ${ }^{22}$ SFT was widely used in children for clinical research and epidemiological purpose, but there are doubts about its validity in infancy. ${ }^{23} \mathrm{BMI}$ is a measure of excess weight relative to height rather than excess body fat, may be less sensitive indicator of fatness among children. ${ }^{24}$ SFT and NC measurements are simple, reasonably precise and attractive methods, they can be used to assess nutritional status in adolescents.

Adolescence is a period of growth spurt and there is an increased demand for energy, protein, minerals and vitamins. Iron deficiency anemia constitutes the major anemia during adolescents and it may affect growth and skeletal development. This is due to rapid pubertal growth with sharp increase in lean body mass, blood volume and red cell mass which increases iron requirements for myoglobin in muscles and hemoglobin in the blood. ${ }^{25}$ The adverse impact gets especially aggravated, if both undernutrition and anemia are present in adolescents.

The rural adolescent girls should be regularly taught about nutritive value of common food items, so that they can cope up with protein, calorie and iron requirements. Key dietary behaviour messages for girls include: eating more than 3 meals a day, eating with family members so as to eat enough, eating green leafy vegetables daily and eating lemon or amla with meals. Iron supplementation programmes need to include nutrition education programmes to be effective. School based nutrition intervention will also work to prevent under nutrition and anemia effectively and efficiently. There should be regular health check up to diagnose and treat undernutrition and anemia early. The government also should establish effective strategies to improve adolescent girls health.

\section{CONCLUSION}

The adolescent girls who had SFT $<14.5 \mathrm{~mm}$ and neck circumference $<27 \mathrm{cms}$ suggesting under nutrition were significantly anemic. SFT and NC can be used as nutritional parameter in adolescent girls. The health and nutritional education should be advocated to rural adolescent girls.

\section{Funding: No funding sources Conflict of interest: None declared \\ Ethical approval: The study was approved by the Institutional Ethics Committee}

\section{REFERENCES}

1. Galloway R. Anemia prevention and control: what works. Part I: Program guidance.2003. Population, Health and Nutrition Information Project (PHNI) Jorge Scientific Corporation, Washington DC.

2. Biradar SS, Biradar SP, Alatagi AC, Wantamutte AS, Malur PE. Prevalence of anemia among adolescent girls: a one year cross sectional study. Journal of Clinical and Diagnostic Research 2012;6(3):372-7.

3. Roy S, Chakravorty PS. Maternal and perinatal outcome in severe anemia. J Obstet Gynae Ind. 1992;42:743-50. 
4. Rangnekar AG, Darbari R. Foetal outcome in anemia during pregnancy. J Obstet Gynae Ind. 1993;43:172-6.

5. Kaur S, Deshmukh PR, Garg BS. Epidemiological correlates of nutritional anemia in adolescent girls of rural Wardha. Indian $\mathbf{J}$ of Community Health Med 2006;31:255-258

6. Gupta A, Parashar A, Thakur A, Sharma D. Anemia among adolescent girls in Shimla hills of North India. Does BMI and onset of menarche have role. Indian J Med Science. 2012;66:126-30.

7. Pinhas-Hamiel O, Newfield RS, Korean I, Agmon A, Lios P, Phillip M. Greater prevalence of iron deficiency in overweight and obese children adolescents. Int $\mathrm{J}$ Obs Relat Metab Discord. 2003;27(3):416-8.

8. Choudhary S, Mishra CP, Shukla KP. Nutritional status of adolescent girls in rural area of Varanasi. Indian Journal of preventive and social medicine. 2003;34(1):54-61.

9. Himes JH, Bouchard C. Validity of anthropometry in classifying youth as obese. International Journal of Obesity. 1989;13:183-93.

10. World Health Organisation. Manual of basic techniques for a health laboratory. 1980:P271-278.

11. DeMayer EM, Dallman P, Gurney JM, Hallberg L, Sood SK, Srikantia SG. Preventing and controlling iron deficiency anemia through primary health care. Geneva: World Health Organisation. 1989:P8-9.

12. DeGruchy GC. General principles in the diagnosis and treatment of anemia. In: Penington D, Rush B, Cataldi P, eds. Clinical haematology in medical practice $4^{\text {th }}$ ed Delhi: CBS Publishers and Distributors; 1986:P59.

13. Chitra B, Nair N, Jose JK, JesinaBegam, Nazar A, Balkrishna. Study on prevalence of anemia among school children in a rural community setup. Sch Acad J Pharm. 2014;3(6):423-26.

14. Peter R, Kumar R, Sangwal L, Pandey S. Prevalence of anemia and its correlation to body mass index: Study among unmarried girls. International Journal of Basic and Applied Medical Sciences. 2012;2(3):58-62.

15. Rawat CMS, Garg SK, Singh JV, Bhatnagar M. Socio Demographic correlates of anemia among adolescent girls in rural areas of district Meerut
(U.P). Indian $\mathrm{J}$ of Community Medicine. 2001;XXVI(4):173-5.

16. National Family Health Survey (NFHS) report 2008. Anemia is on the rise.

17. Agarwal KN, Gomber S, Bisht H, Som M. Anemia prophylaxis in adolescent school girls by weekly or daily iron folate supplementation. Indian Pediatrics 2010;40:296-301.

18. WHO/UNICEF/UNU(2001). Iron deficiency anemia. Assessment, prevention, control. A guide for programme managers. Report of WHO/UNICEF/UNU consultation, 6-10 December 1993, Geneva. Geneva:WHO.

19. Deshpande N, Karva D, Agarkhedkar S, Deshpande S. Prevalence of anemia in adolescent girls and its correlation with demographic factors. International Journal of medicine and public health. 2013;3(4):235-9.

20. Reilly JJ, Wilson J, Durnin JVGA. Determination of body composition from skinfold thickness. Archives of Disease in childhood. 1995;73:305-10.

21. Lipilekha P, Sumitra P, Sahu T, Raovenkata. Overweight and obesity among adolescent. A comparative study between government and private schools. Indian Pediatrics. 2015;52:779-81.

22. Fuller NJ, Jebb SA, Laskey MA, Coward WA, Elia M. A four component model for the assessment of body composition in humans. Clin Sci. 1992;82:687-93.

23. Davies PSW, Lucas A. prediction of body fatness in early infancy. Early Hum Dev. 1989;21:193-8.

24. Reilly JJ, Dorosty AR, Emmett PM. Identification of the obese child: adequacy of the BMI for clinical practice and epidemiology. Int J Obes Relat Metab Disord. 2000;24:1623-27.

25. World Health Organization. Prevention of iron deficiency anemia in adolescents. A role of weekly iron and folic acid supplements. Geneva: World Health Organization:2011.

Cite this article as: Kavthekar S, Chougule A, Kurane A, Kulkarni D. Association between skinfold thickness and neck circumference with anemia in rural school going adolescent girls. Int J Community Med Public Health 2016;3:2197-200. 